\title{
The Rheological Modeling and Effect of Temperature on Steady Shear Flow Behavior of Cordia abyssinica Gum
}

\section{Ali Rafe* and Masood HS}

Department of Food Nanotechnology, Research Institute of Food Science and Technology (RIFST), Mashhad, Iran

\begin{abstract}
Steady shear rheological properties of Cordia abyssinica gum, as a novel hydrocolloid, were investigated at different temperatures $\left(30-50^{\circ} \mathrm{C}\right)$. The apparent viscosity was drastically affected by temperature, and decreased from 234.9 to $7.46 \mathrm{~Pa}$.s. Cordia gum was exhibited pseudoplastic behavior, which being almost Newtonian at $50^{\circ} \mathrm{C}$. Different models including Powerlaw, Herschel-Bulkley and Casson were applied to model rheological trait. The Results were shown that the Herschel-Bulkley model has the best fitness with experimental data. Ascending and descending viscometry data were shown a weak thixotropic behavior particularly at low shear rates. By increasing the temperature in both curves, $\mathrm{n}$ decreased and $\mathrm{k}$ increased. The apparent viscosities of Cordia gum followed an Arrhenius model and the no increased and activation energy diminished as shear rate decreased from 330 to 15/s. Low values of the activation energy implied that Cordia gum can maintain its viscosity at higher temperatures more than BSG and Xanthan. It has a high potential for application in food and neutaceutical products as possess yield stress and pseudoplastic behavior, which enables it to use as an emulsifier, stabilizer or excipient in tablet formulations.
\end{abstract}

Keywords: Cordia gum; Rheology; Modeling; Hydrocolloids; Pseudoplastic

\section{Practical Application}

Cordia gum has a high potential for application in food products such as mayonnaise and salad dressing as an emulsifier or stabilizer. It can also be used in pharmaceutical as a tablet binder.

\section{Introduction}

Hydrocolloids are long chain high molecular weight polymers dissolve or disperse in water and make a thickened or stabilized product. Among all kinds of hydrocolloids, plant polysaccharides, due to the frequency and ease of extraction have gained much interest and are used frequently in many industries. These natural polysaccharides are generally polyuronides composed of more than one type of monosaccharide units $[1,2]$. They are used to improve or manipulate the texture of food products because of their ability to retard flow, modify gelling characteristics, and preserve emulsions and suspensions [3]. They are also widely used in the pharmaceutical and food industry as excipients and additives due to their low toxicity, biodegradable, availability and low cost [4]. They can be modified control of drug delivery release, which influence the absorption and subsequent of bioavailability of the incorporated drug.

Cordia abyssinica is a member of flowering plants belonging to Family Boraginaceae, which is evergreen shrub or small tree. The tree is fast growing and occurs at low altitudes in woodland regions. It was found world widely in warm moist riverside areas, often along riverbanks, especially in north-eastern Africa such as Angola, Mozambique, Zimbabwe and Indo-Pak subcontinent $[5,6]$. C. abyssinica was also grown in the southern region of Iran, particularly at the borderline of the Persian Gulf, Kharg Island, Baluchistan and Khuzestan provinces. It was also found rarely in Tehran (Alborz) and Taleghan mountains.

The fruit of C. abyssinica is a drupe, about 10 to $30 \mathrm{~mm}$ in diameter, which has a globose shape and a sharp tip. It was green when unripe, and turns yellow to orange on ripening season, which occurs between April and December. The shell encloses a sweet mucilaginous flesh, which is highly viscous, and sticky [7]. Rural school children often use the fruit pulp of Cordia as glue, due to its excellent adhesive properties. Although it is edible, but it is not widely consumed by humans and mostly eaten by wild animals [7]. The fruits are used for preparing pickles in Iran and Indo-Pak subcontinent. It has been reported pharmaceutical properties in every part of the tree, particularly fruit pulps. For example, anti-inflammatory constituents have been reported in the seeds [8] and phenolic antioxidants in the fruit extracts $[9,10]$. The mucilaginous extract of the fruit contains an anionic polysaccharide rich in uronic acid [11]. The gum is useful in treating coughs and hyper blood pressure as well as the tablet formulation as a natural binding agents (Shailendra et al. [4]). The gum has been approved as a potential non-toxic and safe pharmaceutical excipient in tablet formulation as well as an excellent emulsifier in food applications [12,13]. Prolongedrelease nano-particles for drug delivery have been prepared from this gum [14]. Due to its better emulsifying and binding properties, it could be used as an effective carrier of additives through the edible coating. So, it was used as a coating based on delaying lipid oxidation of roasted pine nuts [15]. The chemical composition of the Cordia extract was analyzed and it consists primarily of galactose (27\%), rhamnose (21\%), mannose $(17 \%)$, xylose $(11 \%)$, glucose $(10 \%)$, arabinose $(9.5 \%)$, uronic acids (5\%) and approximately $2.6 \%$ protein [11].

Although, some of the chemical and physical properties of Cordia extract were studied, but no research work was performed on its rheological behavior. Due to the unique adhesive properties of the fruit mucilage and high viscosity of the solutions, the Cordia gum has much potential to use as a thickener, stabilizer, emulsifier, table binder and adhesive agent in the food, texture and pharmaceutical industries. In

*Corresponding author: Ali Rafe, Department of Food Nanotechnology, Research Institute of Food Science and Technology (RIFST), PO Box 91735-147, Mashhad, Iran, Tel: +98 511 5003212; Fax: +98 511 5003150; E mail: a.rafe@rifst.ac.ir

Received February 13, 2013; Accepted March 24, 2014; Published April 03, 2014

Citation: Rafe A, Masood HS (2014) The Rheological Modeling and Effect of Temperature on Steady Shear Flow Behavior of Cordia abyssinica Gum. J Food Process Technol 5: 309. doi:10.4172/2157-7110.1000309

Copyright: ( 2014 Rafe A, et al. This is an open-access article distributed under the terms of the Creative Commons Attribution License, which permits unrestricted use, distribution, and reproduction in any medium, provided the original author and source are credited. 
order to exploit gum in different applications, understanding of the rheological behavior of the C. abyssinica is essential. Therefore, the main goal of this research is concerned to the rheological characteristics of Cordia extract and its rheological modeling. Furthermore, the timedependency and effect of temperature on the viscoelastic properties of Cordia gum would be surveyed.

\section{Materials and Methods}

\section{Materials}

Fresh fruits of C. abyssinica were collected between June and July 2013 from Ahvaz suburb, Khuzestan province, Iran and transported to the laboratory, stored at $4 \mathrm{oC}$ and processed within 10 days of collection. Sodium chloride and ethanol were analytical grade and purchased from Sigma (Sigma-Aldrich GmbH, Sternheim, Germany).

\section{Gum extraction}

Gum was isolated from the fruits by hot water extraction and alcohol (ethanol) precipitation. The fruit was squashed manually to release the stones. Then, stones were placed in a strong stainless steel container and well agitated to separate the fruit pulp from the stones as a thick sticky mass. Distilled water was added to this sticky mass and centrifuged in a BHG Hermle 236HK (Bethold Hermle GmbH, Gosheim, Germany) centrifuge at $5000 \mathrm{~g}$ for $30 \mathrm{~min}$ to remove debris. The polysaccharide was precipitated from the mixture by adding two volumes of ethanol in the presence of $0.25 \mathrm{M}$ sodium chloride. The solution of C. abyssinica was prepared at $4 \%(\mathrm{w} / \mathrm{v})$. In order to prevent the microbial growth, sodium azide $0.01 \%$ was added to all solution during the experiments and maintenance.

\section{Rheology measurement}

The rheological properties of solutions were measured using a rotational viscometer (Model DV-III ULTRA, Brookfield Engineering, Inc., USA) at different temperature 30,40 and $50^{\circ} \mathrm{C}$ using the spindle SC4-18 at shear rates from 1 to $330 \mathrm{~s}-1$. Samples were placed in the temperature-controlled measurement vessel and allowed to equilibrate to the defined temperature for $5 \mathrm{~min}$ prior the experiments. The volumes of sample as well as the immersion depth of spindle were kept constant throughout the experiments. The shear rate dependency of steady shear rheological properties of Cordia solutions may be described by different flow models such as Power law, Herschel-Bulkley, Casson, Heinz-Casson and Mizrahi-Berk models [16-18]. Flow behavior of the solutions was described by fitting the experimentally measured shear stress-shear rate data to the power law (1) and Herschel-Bulkely model (2) which, was described as follows:

$$
\begin{aligned}
\tau & =K \gamma^{\cdot \wedge} n \\
\tau & =\tau \_0+K \gamma^{. \wedge} n
\end{aligned}
$$

Where, $\tau$ is shear stress $(\mathrm{Pa}), \gamma$ is the shear rate $(\mathrm{s}-1), \mathrm{k}$ is the consistency coefficient (Pa.sn) and $\mathrm{n}$ is the flow behavior index (dimensionless) and $\tau \_0$ is the yield stress. The effect of temperature on Cordia gum viscosity was studied by an Arrhenius-type equation $[16,19,20]$ :

$$
\eta=\eta_{-} 0 \exp \left(E \frac{a}{R T}\right)(3)
$$

Where, $\eta 0$ is a constant (apparent viscosity at reference temperature, Pa.s), Ea is the activation energy $(\mathrm{J} / \mathrm{mol})$, $\mathrm{T}$ is the absolute temperature $(\mathrm{K})$ and $\mathrm{R}$ is the universal gas constant $(\mathrm{J} / \mathrm{mol} . \mathrm{K})$. All the experiments were performed in triplicate and the data were averaged.

\section{Results and Discussion}

\section{Effect of temperature on the rheological properties of Cordia gum}

The dependency of the apparent viscosity of Cordia gum $(4 \%$ $\mathrm{w} / \mathrm{v})$ to shear rates $(1-330 \mathrm{~s}-1)$ at different temperatures is shown in figure 1 . The apparent viscosity of gum was drastically affected by temperature, and it decreased from 234.9 to $7.46 \mathrm{~Pa}$.s with increasing temperature from 30 to $50^{\circ} \mathrm{C}$. It can also be found, the viscosity of solutions of the polysaccharide decreased with increase in shear rate at all the temperatures and Cordia gum exhibited interesting pseudoplastic behavior. As the temperature was increased exhibition of pseudo-plastic behavior decreased with behavior at $50^{\circ} \mathrm{C}$ being almost Newtonian. When solutions are heated the viscosity decreases as the thermal energy of molecules increases and the intermolecular distances increase. Also, it reflects the expected decrease in chain overlap and entanglement when temperature is increased. A similar decrease in temperature was also observed in other polysaccharides such as pectin, starch and Basil seed gum [21-23].

Shear thinning, as was observed for solutions of C. abyssinica polysaccharide, occurs when the rate of disentanglement by shearing forces becomes greater than the rate of formation of new entanglements and thus the polymer molecules become disentangled, the network is depleted and viscosity is reduced. When shear rate is increased, the polymer molecules would be expected to become disentangled and align themselves in the direction of flow, thus offering less resistance to flow leading to a decrease in viscosity. The degree of pseudo plasticity of solutions of polysaccharide is dependent upon the concentration of the gum, its salt form if it is ionic, and its molecular weight [24]. The molecular weight of C. abyssinica was about $1800 \mathrm{Kda}$ which is more than BSG [25]. Thus, a gum solution may have almost Newtonian behavior at low concentration and pseudoplastic flow after the 'break point' in concentration is reached. In general, solutions of high molecular weight polysaccharides are more pseudoplastic and therefore, more affected by shear than low molecular weight gums.

In addition, the apparent viscosity decreasing intensely at low shear rate (from 1-70 s-1) and less rapidly at higher shear rate range (70-330 s-1). At low shear rates, Newtonian region was not detected showing that the zero-shear viscosity could exist at these shear rates. In general,

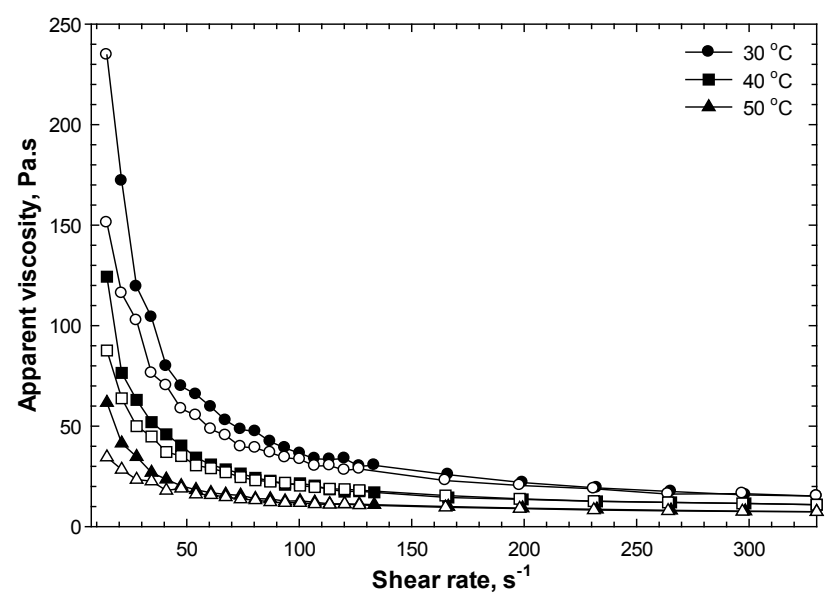

Figure 1: Effect of temperature on shear thinning behavior of Cordia gum in asecnding (filled symbols) and descending (empty symbols) curves. 
polysaccharide molecules with stiff conformation contribute to high zero-shear rate viscosity and possess strong shear-thinning properties. This is because stiff polymer molecules are quickly aligned in the direction of flow as the shear rate increases and therefore physical interactions between adjacent polymer chains decrease. A high shear thinning behavior of polysaccharides allows liquid foods to be pumped easily and imparts a thinner consistency during swallowing [26]. Szczesniak and Farkas [27] have shown correlation a higher degree of shear thinning with a lower degree of sliminess in the mouth produced by hydrocolloids [27]. The same rheological behavior was obtained for Basil Seed Gum (BSG) solutions at different concentrations [23]. Since, the viscosity of Cordia gum was decreased more sharply than a BSG solution at shear rate range (1-50 s-1) indicating Cordia gum possess high zero shear viscosity. Consequently, the mouth feel characteristics of Cordia may be even better than BSG, CMC, pectin, carrageenan or mono-hydrocolloid based on the higher shear-thinning properties $[23,17,26,28,29]$. The improving of rheological characteristics of solutions depends on the distribution of molecular weight, the degree of hydration of the hydrocolloids molecules, the extent of interaction with different molecules or molecules of the same type, concentration of the polymer and environmental conditions, such as temperature and the presence of other types of molecules [30].

\section{Modeling of rheological behavior}

In order to fit the data using rheological models, Dervisoglu and Kokini [31] suggested using two different models including at low and high shear rates. Moreover, the range of shear rate being considered in the modeling can result in different values of the rheological parameters (e.g. different $\mathrm{n}$ and $\mathrm{K}$ values). The log-log plot of apparent viscosity versus shear rate was shown in figure 2 . There was a nearly linear relationship between the log of the apparent viscosity ( $\eta \mathrm{pa})$ and the log of the shear rate $(\gamma)$ at shear rates and temperatures included in this study. The slope of the curve was high initially $(0.037-0.045)$ and decreased with increasing shear rate (0.029-0.034). The turn point of slope curve was obtained at shear rate about 133s-1. The linear shape of the log graphs was consistent with those observed for higher molecular weight polysaccharides and characterises the pseudoplastic behavior of the solutions [32]. Similarly, linear plots were observed when double logarithmic plots relating viscosity to shear rates were made when studying the effect of $\mathrm{pH}$ and salts on viscosity of C. abyssinica [25]. The effect of temperature on rheological parameters of Cordia gum solutions based on Power law equation was shown in table 1. It can be seen, $\mathrm{n}$ decreased and $\mathrm{k}$ increased as temperature was increased. However, the correlation coefficient of this model for Cordia gum was nearly good at this shear rate range (1-330s-1) and temperatures, but it was stated that although the pseudo-plastic behavior of many polysaccharides can be fitted by the Power law equation and provides a reasonably linear fit over several decades of shear rates, it is inadequate if a wide range of shear rates is to be examined [33]. Therefore, other models such as Herschel-Bulkley and Casson were also explored.

For polysaccharides that exhibit yield stress such as xanthan gum $[17,18]$, models that include yield stress terms are more adequate. From the flow curves, Cordia polysaccharide showed the presence of yield stress (Figure 3). It can be found, shear stress values decreased at low shear rates which, can be interpreted as the result of the existence of a static/dynamic yield stress. So, the Herschel-Bulkley model was applied in rheological modeling. Among the rheological models, the Herschel-Bulkley equation gave the best fit for the flow behavior of Cordia gum in the shear rate range of 1-330 s-1. The flow behavior index $(\mathrm{n})$ and consistency coefficient $(\mathrm{K})$ values obtained using the Herschel-Bulkley model in both upward and downward curves at different temperatures were presented in table 2 . These values showed a weak thixotropic behavior particularly at low shear rates, due to the differences between $\mathrm{n}$ and $\mathrm{K}$ in upward and downward curves $(\mathrm{p}<0.05)$. The order of magnitudes of flow behavior index ranged between $1.06-1.27$ and $0.703-0.770$ at different temperatures $\left(30-50^{\circ} \mathrm{C}\right)$

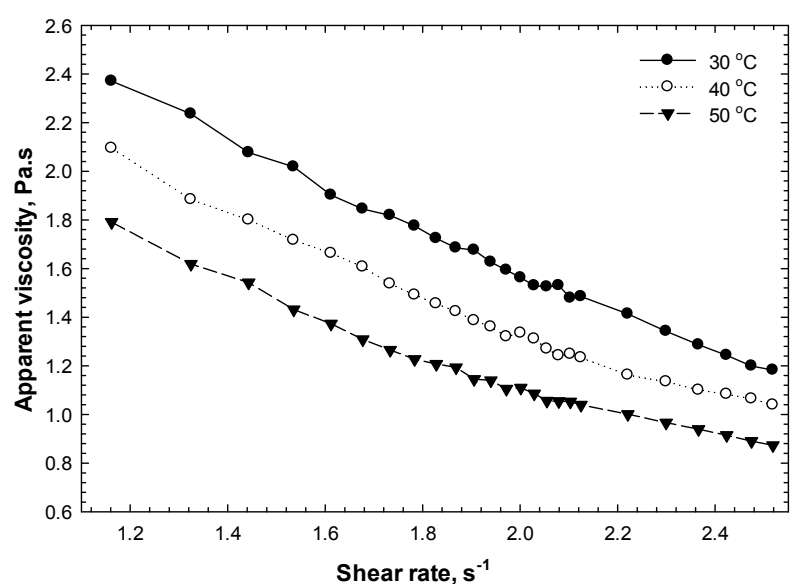

Figure 2: The logarithmatic plot of apparent viscosity $\left(\eta_{a p}\right)$ versus shear rate ( ) at different temperatures.

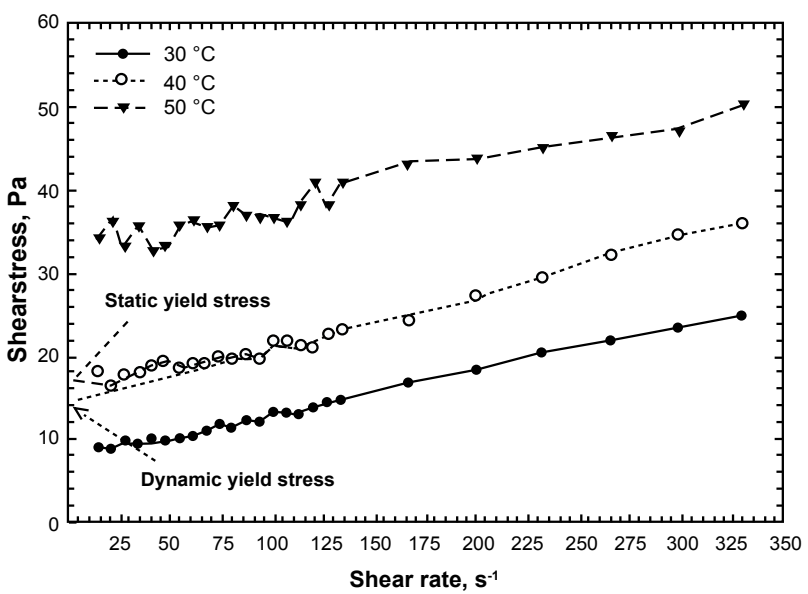

Figure 3: Illustration of dynamic and static yield stress in C. abyssinica by using shear stress-shear rate curve.

\begin{tabular}{|c|c|c|c|c|c|c|}
\hline \multirow{2}{*}{ Temperature $\left({ }^{\circ} \mathrm{C}\right)$} & \multicolumn{3}{|c|}{ Ascending curve } & \multicolumn{3}{|c|}{ Descending curve } \\
\hline & $\mathrm{n}(-)$ & $K\left(P a . s^{n)}\right.$ & $\mathbf{R}^{2}$ & $n(-)$ & $K\left(P a . s^{n}\right)$ & $\mathbf{R}^{2}$ \\
\hline 30 & $0.44 \pm 0.05$ & $1.72 \pm 0.44$ & 94.18 & $0.53 \pm 0.03$ & $1.05 \pm 0.14$ & 99.02 \\
\hline 40 & $0.29 \pm 0.05$ & $5.69 \pm 1.55$ & 83.76 & $0.37 \pm 0.03$ & $3.77 \pm 0.55$ & 97.11 \\
\hline 50 & $0.14 \pm 0.06$ & $20.49 \pm 2.81$ & 78.91 & $0.25 \pm 0.02$ & $10.74 \pm 1.52$ & 93.52 \\
\hline
\end{tabular}

Table 1: Effect of temperature on rheological parameters of Cordia gum solutions based on Power law model. 
Citation: Rafe A, Masood HS (2014) The Rheological Modeling and Effect of Temperature on Steady Shear Flow Behavior of Cordia abyssinica Gum. J Food Process Technol 5: 309. doi:10.4172/2157-7110.1000309

Page 4 of 5

\begin{tabular}{|c|c|c|c|c|c|c|c|}
\hline \multirow{2}{*}{ Temperature $\left({ }^{\circ} \mathrm{C}\right)$} & \multirow{2}{*}{$(\mathrm{Pa})$} & \multicolumn{3}{|c|}{ Ascending curve } & \multicolumn{3}{|c|}{ Descending curve } \\
\hline & & $n(-)$ & $K\left(P a \cdot s^{n}\right)$ & $\mathbf{R}^{2}$ & $n(-)$ & K(Pa.s $\left.\mathbf{s}^{n}\right)$ & $\mathbf{R}^{2}$ \\
\hline 30 & $7.79 \pm 0.59$ & $1.06 \pm 0.10$ & $0.036 \pm 0.02$ & 99.38 & $0.703 \pm 0.07$ & $0.322 \pm 0.25$ & 99.6 \\
\hline 40 & $17.02 \pm 0.69$ & $1.18 \pm 0.17$ & $0.034 \pm 0.01$ & 98.87 & $0.719 \pm 0.06$ & $0.312 \pm 0.21$ & 99.73 \\
\hline 50 & $32.94 \pm 2.04$ & $1.27 \pm 0.36$ & $0.032 \pm 0.01$ & 97.47 & $0.770 \pm 0.22$ & $0.293 \pm 0.05$ & 96.72 \\
\hline
\end{tabular}

Table 2: Effect of temperature on rheological parameters of Cordia gum solutions based on Herschel-Bulkley model.

for the upward and downward curves, respectively. Also, consistency coefficient (K) was 0.032-0.036 and 0.293-0.322 Pa.sn for the upward and downward curves, respectively. By increasing the temperature from 30 to $50 \mathrm{oC}$ in both curves, $\mathrm{n}$ decreased and $\mathrm{K}$ increased. The reduction of the flow behavior index with increasing temperature indicates more pseudoplasticity at low shear rates [26]. In comparison with Cordia Gum, in BSG solutions, $\mathrm{n}$ increased and $\mathrm{K}$ decreased from 5 to $85^{\circ} \mathrm{C}$ [23]. The increasing of the flow behavior index with increasing temperature was also obtained for Monoi gum, guar gum [26] and carrageenan [17].

The values of the static yield stress obtained by extrapolation in figure 3 were $8.14,16.80$ and 33.39 at 30,40 and $50^{\circ} \mathrm{C}$ temperatures, respectively. These values were significantly more than the magnitudes of the dynamic yield stress determined by fitting the data using the Herschel-Bulkley model (Table 2). The presence of yield stress implies that Cordia gum has high suspension's ability which is a useful property when used as a stabilizer in food products such as mayonnaise and salad dressings. This is the reason for xanthan which exhibits yield stress $[17,18]$, to be commonly used in colloidal systems, where the long-term stability is markedly increased with its addition [34]. From a process design point of view, the magnitude of yield stress is related to the amount of material retained on the walls of containers and transportation vessels which may sometimes be undesirable [17].

The apparent viscosities of Cordia gum at temperatures 30, 40 and $50^{\circ} \mathrm{C}$ followed an Arrhenius type model (Fig. 4). Arrhenius Parameters including frequency factors ( $\eta$ o), activation energies (Ea) and coefficients of determination (R2) at shear rates 15, 40, 60, 100, 120 and $330 \mathrm{~s}-1$ are presented in table 3 . The magnitude of $\eta$ o increased from $21.9 \times 10-3$ to $459 \times 10-3$ as shear rate decreased from 330 to $15 / \mathrm{s}$. A reduction in activation energy was also observed with increasing shear rates. As shown in figure 4 , slope values were relatively low at all shear rates which is related to low activation energy of Cordia gum. The activation energy of BSG at $2 \%$ was reported about $5000 \mathrm{~J} / \mathrm{mol}$ at shear rate $100 / \mathrm{s}$ which is more than Cordia gum at the same shear rate. Low values of the activation energy imply that the Cordia gum can maintain its viscosity at higher temperatures. Gums such as xanthan $(\mathrm{Ea}=5740$ $\mathrm{J} / \mathrm{mol}$ ) have been reported to be temperature stable by Marcotte et al. [17], Sworn and Rocks [17,35,36]. However, a decrease in viscosity by $50 \%$ from 20 to $80^{\circ} \mathrm{C}$ has been detected in galactomannans [37]. It seems Cordia gum have proper rheological behavior which, enables it to apply in food formulation and processing.

\section{Conclusion}

The rheological properties of Cordia Abyssinica gum as a novel hydrocolloid is required if it would be applied in the food, pharmaceutical and textile industries. The apparent viscosity of gum was drastically affected by temperature, and decreased from 234.9 to 7.46 Pa.s by increasing temperature. It was exhibited weak thixotropic behavior particularly at low shear rates which became almost Newtonian at $50^{\circ} \mathrm{C}$. In comparison with BSG, Cordia posses high zero shear viscosity. The Herschel-Bulkely model was found the most suitable rheological model to characterize flow behavior of

\begin{tabular}{|c|c|c|c|}
\hline Shear rates, $\mathbf{s}^{-1}$ & $\mathbf{n}_{\mathbf{o}}, \mathbf{P a} . \mathbf{s}$ & $\mathbf{E}_{\mathbf{a}}, \mathbf{J} / \mathbf{m o l}$ & $\mathbf{R}^{\mathbf{2}}$ \\
\hline 15 & $459^{*} 10^{-3}$ & 5487.27 & 0.99 \\
\hline 40 & $148^{*} 10^{-3}$ & 5063.22 & 0.99 \\
\hline 60 & $109^{*} 10^{-3}$ & 5019.16 & 0.99 \\
\hline 100 & $60.9^{*} 10^{-3}$ & 4323.28 & 0.999 \\
\hline 120 & $56.3^{*} 10^{-3}$ & 4489.56 & 0.98 \\
\hline 330 & $21.9^{*} 10^{-3}$ & 2963.94 & 0.99 \\
\hline
\end{tabular}

Table 3: Temperature dependency of apparent viscosity at different shear rates of Cordia gum based on Arrhenius-type equation.

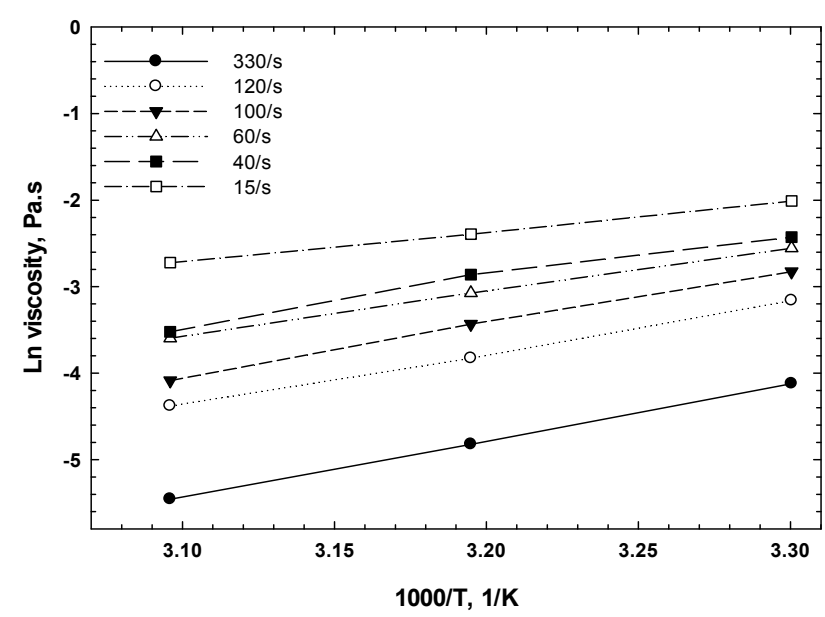

Figure 4: Temperature dependency of Cordia gum viscosity at different shear rates using Arrhenius equation.

Cordia gum. The pseudoplacticity decreased and consistency increased with increasing temperature. The activation energy of Cordia gum was less than BSG and xanthan gum which implies that it could maintain viscosity at higher temperatures. The presence of a high yield stress and high pseudoplastic behavior of Cordia could qualify it as a good stabilizer in food formulations such as mayonnaise and salad dressing. Further work is underway to understand the dynamic rheological behavior and it gelling ability at different conditions.

\section{References}

1. Sharma SC (1981) Gums and hydrocolloids in oil water emulsions. Food Technology 1: 59-67.

2. Zapsalls C, Berck RA (1985) Food chemistry and rheological properties of hydrocolloids. New York: John Wiley.

3. Balmaceda E, Rha C, Huang F (1973) Rheological properties of hydrocolloids Journal of Food Science 38: 1169-1173.

4. Shailendra P, Shikha A, Singh LB (2012) Natural Binding Agents in Tablet Formulation. International Journal of Pharmaceutical \& Biological Archives 3: 466-473.

5. Van Wyk B, Van Wyk P (1998) Field guide to trees of southern Africa. Cape Town: Struik Publishers (Pty) Ltd.

6. Siddiqui BS, Perwaiz S, Begum S (2006) Studies on the chemical constituents of the fruits of Cordia latifolia. Natural Product Research 20: 131-137.

7. Benhura M, Chidewe C (2002) Some properties of a polysaccharide preparation that is isolated from the fruit of Cordia abyssinica. Food chemistry 76: 343-347. 
Citation: Rafe A, Masood HS (2014) The Rheological Modeling and Effect of Temperature on Steady Shear Flow Behavior of Cordia abyssinica Gum. J Food Process Technol 5: 309. doi:10.4172/2157-7110.1000309

8. Agnihotri VK, Srivastava S D, Srivastava SK, Pitre S, Rusia K (1987) Constituents from the seeds of Cordia obliqua as potential anti-inflammatory agents. Indian Journal of Pharmaceutical Sciences 49: 66-69.

9. Afzal M, Obuekwe C, Khan AR, Barakat H (2007) Antioxidant activity of Cordia myxa $L$. and its hepatoprotective potential. Electronic Journal of Environmental, Agricultural and Food Chemistry 6: 2109-2118

10. Souri E, Amin G, Farsam H, Barazandeh-Tehrani M (2008) Screening of antioxidant activity and phenolic content of 24 medicinal plant extracts. DARU Journal of Pharmaceutical Sciences 16: 83-87.

11. Benhura M, Katayi-Chidewe C (2004) The emulsifying properties of a polysaccharide isolated from the fruit of Cordia abyssinica. International Journal of Food Science and Technology 39: 579-583.

12. Mukherjee B.Dinda SC (2007) New use of natural gum cordia and new modified gum cordia-as pharmaceutical excipients and a new modified gum cordia and its use for enteric resistant, sustained and controlled release agent and also as other pharmaceutical excipients. Indian Pat. Off. J 6-1:14699.

13. Mukherjee B, Dinda SC, Barik BB (2007) Gum Cordia: A Novel Matrix Forming Material for Enteric resistant and Sustained Drug Delivery-A Technical Note.

14. Ahuja M, Yadav M, Kumar S (2010) Application of response surface methodology to formulation of ionotropically gelled gum Cordia/gellan beads. Carbohydrate Polymers 80: 161-167.

15. Haq MA, Alam MJ, Hasnain A (2013) Gum Cordia: A novel edible coating to increase the shelf life of Chilgoza (Pinus gerardiana). Journal of Food science and technology, 50: 306-311.

16. Rao MA, Kenny JF (1975) Flow properties of selected food gums. Canadian Institute Food Science Technology Journal 8: 142-148.

17. Marcotte M, Taherian AR, Ramaswamy HS (2001) Rheological properties of selected hydrocolloids as a function of concentration and temperature. Food Research International 34: 695-704

18. Song KW, Kim YS, Chang GS (2006) Rheology of concentrated xanthan gum solutions: Steady shear flow behavior. Fibers and Polymers 7: 129-138.

19. Rao MA, Anantheswaran RC (1982) Rheology of fluid in food processing. Food Technology 36: 116-126

20. Speers RA, Tung MA (1986) Concentration and temperature dependence of flow behavior of xanthan gum dispersions. Journal of Food Science 51: 96-98.

21. Kar F, Arslan N (1999) Effect of temperature and concentration on viscosity of orange peel pectin solutions and intrinsic viscosity-molecular weight relationship. Carbohydrate Polymers 40: 277-284.

22. Abu-Jdayil B, Mohameed A, Eassa A (2004) Rheology of starch-milk-sugar systems: Effect of heating temperature. Carbohydrate Polymers 55: 307-314.
23. Hosseini-Parvar SH, Matia-Merino L, Goh KKT, Razavi SMA Mortazavi SA (2010) Steady shear flow behavior of gum extracted from Ocimum basilicum L. seed: Effect of concentration and temperature. Journal of Food Engineering 101: $236-243$

24. Whistler RL, BeMiller JN (1997) Behaviors of polysaccharide solutions, dispersions and gels. In, Carbohydrate Chemistry for Food Scientists. Eagan Press, New York.

25. Katayi-Chidewe C (2004) Characteristion of the polysachharide material isolated from the fruit of Cordia Abyssinica, phD thesis, University of Zimbabwe.

26. Vardhanabhuti B, Ikeda S (2006) Isolation and characterization of hydrocolloids from monoi (Cissampelos pareira) leaves. Food Hydrocolloids 20: 885-891.

27. Szczesniak AS, Farkas E (1962) Objective characterization of the mouthful of gum solutions. Journal of Food Science 27: 381-385.

28. Riazi A, Farhoosh R, Razavi SMA (2006) An investigation on rheological properties of the gum from two current varieties of Salep in Iran. M.Sc thesis, Ferdowsi University of Mashhad, Iran.

29. Feng T, Gu ZB, Jin ZY (2007) Chemical composition and some rheological properties of Mesona blumes gum. Food Science and Technology International 13: $55-61$.

30. Krumel KF, Sarkar N (1975) Flow properties of gums useful to the food industry Food technology 29: 36-44

31. Dervisoglu M, Kokini JL (1986) Steady shear rheology and fluid mechanics of four semi-solid foods. Journal of Food Science 51: 541-546.

32. Guizani N, Kasapis S, Al-Ruzeik M (2001) Microbial, chemical and rheological properties of laban (cultured milk). International Journal of Food Science and Technology 36: 199-205.

33. Morris ER (1989) Polysaccharide solution properties: origin, rheological characterization and implication for food systems. Frontiers in Carbohydrate Research, 1: Food applications. Elsevier Applied Science, London.

34. Hibberd DI, Howe AM, Mackie AR, Purdy PW, Robins MM (1987) Measurements of creaming profiles in oil-in-water emulsions. Food Emulsions and Foams. The Royal Society of Chemistry, London.

35. Sworn G (2000) Xanthan gum. Handbook of Hydrocolloids. Wood head Publishing Limited, Cambridge.

36. Rocks JK (1971) Xanthan gum. Food Technology 25: 476-483.

37. Wielinga WC (2000) Galactomannans. Handbook of Hydrocolloids. Woodhead Publishing Limited, Cambridge. 